\title{
Review
}

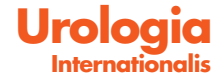

Piotr Zapała

Bartosz Dybowski

Sławomir Poletajew

Piotr Radziszewski

Department of General, Oncological and Functional Urology, Medical University

of Warsaw, Warsaw, Poland

\section{What Can Be Expected from Prostate Cancer Biomarkers? A Clinical Perspective}

\section{Keywords}

Biomarkers · Molecular tests · Prostate cancer · Screening · Panel tests

\section{Abstract}

Along with significant advances in prostate cancer biology research, we also observe the rapid development of modern diagnostic tests. New biomarkers are derived to detect disease while it is organ-confined to stratify the risk and to aid clinical decision-making. Majority of these tools have already been validated clinically, but only a few have received premarket clearance and administration approval. Superiority of novel tests is visible not only in improved detection accuracy but predominantly in the assessment of tumour aggressiveness and selection of patients eligible for conservative management. Two factors limiting the clinical implementation of validated biomarker candidates are costs and local availability. For these reasons, currently, their true clinical role starts after routine screening with prostate-specific antigen test. With this review of prostate cancer biomarkers, we attempted to draw general conclusions on clinical perspectives of these novel tools.

\section{Introduction}

\section{Prostate Cancer Screening - Benefits and Harms}

Prostate cancer ( $\mathrm{PCa})$ is the most common non-skin cancer in elderly males in Europe. Although it is more frequently found in northern and western Europe $(>200$ per 100,000), in eastern and southern Europe, PCa is showing a constant growing tendency and in upcoming years, it may reach the rates that are prevalent in western and northern parts of the country [1]. The asymptomatic presentation of localized PCa constitutes a strong rationale for screening. Prostate-specific antigen (PSA) testing in men with lower urinary tract symptoms as well as in asymptomatic men resulted in a strong increase of detection rates and incidence of this neoplasm in European population. Although large European studies confirm $21 \%$ reduction in disease-specific fatalities after 13 years of follow-up [2], the survival benefit of PSA screening has been questioned in the US population [3]. PSA level of $4 \mathrm{ng} / \mathrm{mL}$ has been challenged even earlier, as $20-25 \%$ men diagnosed with PCa including those with poorly differentiated one (Gleason Score $[G S] \geq 8$ ) have PSA below this threshold [4]. Moreover, although it shows high organ specificity, PSA is not cancer-specific, which results in el-

\section{KARGER}

(c) 2017 S. Karger AG, Basel

E-Mail karger@karger.com

www.karger.com/uin
Bartosz Dybowski, MD, PhD

Department of General, Oncological and Functional Urology Medical University of Warsaw

Lindleya 4, PL-02-005 Warsaw (Poland)

E-Mail bartosz.dybowski@wum.edu.pl 
evated serum concentration among patients with benign hyperplasia, urogenital infections or transurethral manipulations. As PSA enzymology seems to evolve during oncogenesis and many PSA variants might be secreted depending on mutated cells population [5], the old diagnostic approach to PSA as a "solo" biomarker slowly fades out. These concerns as well as the significant over-detection and over-treatment trends generated with PSA screening $[3,6]$ resulted in extensive research for PSA replacement or its improvement with panel tests or novel nomograms. Recent efforts focus on finding biomarkers that could distinguish aggressive forms of cancer from indolent ones, as both PSA screening and pathological grading with GS fail to assess tumour aggressiveness with satisfactory accuracy. Similar to the use of multiparametric MRI for targeting prostate biopsy [7], some modern tests seem to have the potential to limit the detection of indolent disease both in patients with a prior negative biopsy and men who have never been biopsied before.

\section{Discussion}

\section{PSA and Its First Derivatives - Does It Really Make} a Difference?

According to guidelines of European Association of Urology [8], PSA testing should be offered as a part of risk-adapted strategy for early detection of PCa based on age, race, previous PSA levels and life expectancy. Further risk-assessment with risk calculators/tables, additional serum- or urine-based test or imaging is advised in asymptomatic individuals with PSA between 2 and 10 $\mathrm{ng} / \mathrm{mL}$ prior to prostate biopsy. The value of PSA measurements repeated in time (PSA velocity - PSAV, PSA doubling time-PSADT) is disputable and does not seem to overcome standard PSA test [9], although PSAV might be of value in PCa significance stratification in particular individuals $[10,11]$. In selecting patients eligible for active surveillance (AS) PSA serum levels divided by the TRUS - or MRI - determined prostate volume (PSA density [PSAD]) might be of particular value [12]. However, what remains controversial about placing PSAD within AS criteria is setting cut-offs.

In addition to PSAD and PSA kinetics based on standard assay, some analytical variants of PSA test might be implemented. PSA detected in serum is either bonded with macromolecules or in its free form - free PSA (fPSA). Although the ratio of free to total PSA (tPSA) is known to be lower in men with $\mathrm{PCa}$ [13] and can reduce unnecessary biopsies with mild loss in PCa detection sensitivity
[14], fPSA molecule is highly unstable when compared to tPSA, which results in variable analytic outcome [15]. Despite advances in this matter in recent years, detection rates might greatly differ depending on the assay used, and further standardization analyses are still required [16]. Taking this into account, the use of fPSA for primary screening is not advised, although in particular individuals' fPSA seems to be a useful adjunct to standard PSA test, both the diagnostic and the prognostic one. The cut-off level of \%fPSA $\leq 15$ as a biopsy indication improves $\mathrm{PCa}$ detection rates in men with normal digital rectal examination (DRE) and PSA 2.5-4.0 ng/mL [17]. In patients with clinically localized PCa and PSA 4-10 ng/ $\mathrm{mL}$, reduction in $\mathrm{PSSA} / \mathrm{tPSA}$ ratio may be a predictor of extracapsular tumour extension and biochemical recurrence (BCR) [18].

Another PSA-derived biomarker, pro-PSA, is the proenzymatic, zymogen form of PSA, cleaved by human kallikrein (hK) enzymes (mainly hK-2 and hK-4) to its mature form. The measurement of isoform of pro-PSA ([-2] pro-PSA) in combination with free and tPSA was used to construct Prostate Health Index (PHI) panel test approved by Food and Drug Administration (FDA) in 2012. Pro-PSA and PHI achieve higher detection accuracy than tPSA, \%fPSA or PSAD especially in men with PSA ranging from 2-10 ng/mL $[19,20]$. Pro-PSA and PHI can also reduce the number of negative biopsies improving the cost-effectiveness of PCa detection [21] and seem to be a specific tool in biopsy-naive population [22]. proPSA-derivatives have emerged as successful tools to predict tumour aggressiveness and distinguish $\mathrm{PCa}$ from $\mathrm{BPH}$ or prostatitis as well as differentiate nonneoplastic lesions [23-26]. Preoperative PHI may predict BCR and pathological features with even better prognostic accuracy than other FDA-approved biomarkers [27-29]. Although due to obvious reasons proPSA is no replacement for imaging diagnostics in predicting PCa $[30,31]$, combining MRI with proPSA seems to improve its predictive values in biopsy-naive men [32]. Whether the use of PHI is associated with the benefit for clinical decision-making is yet to be established [29].

\section{K Score - Does More Mean Better?}

The $4 \mathrm{~K}$ score test (Opko Health Inc.) includes the panel of 4 kallikrein proteins (fPSA, tPSA, iPSA, and hK2) plasma levels and has also been developed to differentiate between patients with aggressive PCa eligible for biopsy and those with low risk and benign lesions [33, 34]. Similarly to PHI, the potential of kallikreins combination to improve detection specificity and thus reduce costs has 
already been recognized [35]. Although in comparison with PCA3, 4K test seems to possess a less encouraging predictive value, both of them may improve detection with the European Randomised Study of Screening for Prostate Cancer risk calculator in prescreened men [36]. In another recent study, $4 \mathrm{~K}$ score was as accurate and specific in predicting PCa and GS $\geq 7 \mathrm{PCa}$ as $\mathrm{PHI}$ [37]. Implementation of $4 \mathrm{~K}$ test was recently proposed in men $>50$ years of age in top $10-25 \%$ of PSA values to detect metastatic disease as well as to provide biopsy decision support in uncertain cases with elevated PSA [38]. Although $4 \mathrm{~K}$ score test is yet to be approved by FDA, it is already offered as a Laboratory Developed Test by CLIA-Certified and CAP-Accredited laboratories.

\section{Prostate Cancer Antigen 3 - Replacing Protein}

\section{Detection with Transcript Tests?}

Prostate cancer antigen 3 (PCA3 or DD3) was one of the first long non-coding RNA PCa-specific biomarkers developed and marketed [39]. PCA3 possesses some interesting involvement in PCa pathomechanism and has been therefore widely studied to date. Recently, it has been shown that PCA3 RNA expression is under the strong influence of androgens [40]. Progensa PCA3 urine detection assay (Hologic) based on in-vitro nucleic acid quantitative amplification (reverse transcription polymerase chaining reaction [RT-PCR]) [41] has been approved by FDA in 2012 for men with negative PSA/biopsy/DRE. The ratio of PCA3 mRNA molecules to PSA mRNA molecules in urine specimens is calculated. In Progensa assay, specimens can be obtained after immediate DRE; however, recently proposed novel molecular PCA3/ERG signature can also be derived from non-DRE urine after extracting RNA from exosomes (EXO106 score - discussed later) [42]. Another technical problem of RNA instability has also been addressed recently, as RNA extraction efficiency can be potentially improved with novel RNA sequence-specific capture resulting in better sensitivity and specificity [43]. In a majority of studies performed with Progensa, PCA3 score of $<25 \mathrm{im}$ plies low risk of PCa $[34,44-46]$. The meta-analysis on multi-centre European prospective studies confirmed however that clinical aid brought by PCA3 does not end with detection of cancer but also includes stratification of its significance [47]. In combination with traditional tools like Epstein criteria, PCA3 emerged as an attractive test to guide clinical decisions on AS or prostatectomy. Similarly to PHI and $4 \mathrm{~K}$-score test, the implementation of PCA3 has shown potential to lower the number of unnecessary biopsies and reduce costs [48]. The choice of PCA3 as a leading biomarker for screening has its own problems. Although in a double-blind PCA3 vs. PHI study, PCA3 seems to outperform PHI in cancer prediction accuracy, PHI remains the most accurate predictor when screening exclusively for significant $\mathrm{PCa}$; thus, in population screening, authors recommend the use of PHI rather than PCA3 [49]. In a repeated biopsies environment, multiparametric MRI grading combined with PCA3 score are associated with better PCa detection rates [50, 51] and in men eligible for AS, PCA3 can improve the prognostic performance of PRIAS and Epstein criteria for insignificant $\mathrm{PCa}$ [52]. Hansen et al. [53] proved that the use of PCA3 within nomogram might improve the accuracy of the clinical model by $4.5-7.1 \%$ when predicting the risk of harboring PCa at initial biopsy. After its promising initial performance, the nomogram combining established clinical risk factors (age, DRE, prostate volume, PSA) with PCA3 has been successfully validated externally [54]. With $40 \%$ probability threshold set in the validation cohort, almost half $(49.1 \%)$ of initial biopsies would have been saved at a cost of missing only $16 \%$ of HGPCa (high-grade PCa). Recently, internal validation of a novel PCA3-based nomogram in initial biopsy setting was performed [55]. In addition to previously analyzed variables (age, digital rectal exam, prostate volume, PSA), the new model incorporated race and family history of PCa. The nomogram yielded high predictive accuracy with a concordance index of 0.742 and 0.768 for probability of PCa and HGPCa respectively. These and other similar studies support the concept of using PCA3 and clinical data combination as a powerful decision support tool.

\section{Oncotype DX and Genomic Prostate Score - Novel Tools from Breast Oncology}

Oncotype DX developed by Genomic Health is a quantitative RT-PCR test performed on paraffin-embedded biopsy specimens detecting the panel of 12 cancer genes involved in 4 fields crucial for oncogenesis. Genepanel was derived from signaling pathways relevant to stromal response (BGN, COL1A1 and SFRP4), proliferation (TPX2), androgen receptor pathway (AZGP1, KLK2, SRD5A2, and RAM13C) and cellular organization (FLNC, GSN, TPM2, and GSTM2) - all normalized to 5 reference genes $[34,56]$. Oncotype DX has been originally developed as a valuable predictive tool in detecting breast cancer, but to date it has also been analyzed in cohorts of men diagnosed with low or low-intermediate risk PCa who might be candidates for AS [57, 58]. Algorithmic combination is used to calculate Genomic Prostate Score (GPS) that ranges from 0 to 100 , with higher scores 
validated to be associated with high-grade $\mathrm{PCa}$ and higher staging (OR per 20 GPS units: 2.3; and 1.9 respectively) [57]. High GPS predicts adverse pathology and also BCR and time to metastases (OR per 20 GPS units 3.3, 2.9 and 3.8 respectively) [58].

Prolaris and Cell-Cycle Progression - A Molecular

Player among Risk Calculators

Prolaris (Myriad Genetics) is another molecular-based (RT-PCR) prognostic test measuring the expression of 31 cell-cycle progression (CCP) genes. The test is performed on paraffin-embedded specimens. Analytical outcome is represented by the CCP score correlated with the proliferation index of $\mathrm{PCa}$ and serving as the postoperative risk stratification tool [34]. In the first 2 validation studies by Cuzick et al. [59, 60], CCP was the strongest prognostic factor in a multivariate analysis for predicting BCR and time to PCa-specific death. Next, external validation of Prolaris performed by different teams included the comparison of CCP with standard postoperative recurrence risk assessment (Cancer of the Prostate Risk Assessment post-Surgical [CAPRA-S]) and combination of both scores [61]. CCP expressed better prognostic values (HR 2.1 for each unit increase) than CAPRA-S (HR 1.7) and combined CCP/CAPRA-S outperformed individual scores on decision curve analysis. After observing an encouraging outcome of combining CCP with clinicopathological markers in this and similar studies [62, 63], previously mentioned team validated clinical-cell-cycle-risk score in the group of 585 men. Clinical-cell-cycle-risk score was developed as a linear combination of the CCP score and clinical variables included in the CAPRA score [64]. Initial experience suggests that CCP might be even more accurate when combined with 3D-documented biopsy-mapping technology [65]. Finally, recently published meta-analysis provides strong evidence that the use of the CCP score improves treating-decision and constitutes a clinically useful prognostic tool [66]. The economic analysis of CCP implementation is yet to be performed and would be of great value.

\section{Decipher and Genomic Classifier-Know Your Enemy to Change Tactics}

Decipher developed by Genome Dx Biosciences and Mayo Clinic is a genomic test based on the panel of RNA biomarkers involved in multiple signaling pathways relevant to prostate oncogenesis (immune modulation, proliferation, adhesion and motility, cell differentiation, CCP and androgen signaling). Based on the expression of 22 genes, genomic classifier (GC) score is calculated [67].
GC was developed as a prognostic tool to assess the probability of metastatic disease development after RP and eventually change secondary treatment recommendations including post-RP adjuvant radiation therapy [34, 67-72]. Based on the PRO-ACT study from 2014, even $60 \%$ of post RP high-risk patients might be reclassified with GC, 30\% patients might need additional adjuvant treatment and in $40 \%$, adjuvant therapy might be unnecessary in spite of initial recommendations [73]. Moreover, the predictive value of GC is not limited to post-RP patients but can be utilized in recurrent individuals who underwent RP and have already been treated with secondary salvage RT [74]. Similarly to Prolaris, GC scoring adds a significant predictive value to the clinical scoring (CAPRA-S) as well as to the Eggeners risk model, which constitutes the rationale for genomic-clinical classifier integration $[72,73,75]$. In a recent prospective study on a large cohort of 2,342 patients, utilization of the GC score in postoperative decision-making changed initial tumour aggressiveness classification based on clinical parameters alone [76], regardless of the positive correlation between Decipher score and GS, T-staging, CAPRA-S, and age. In fact, the relation between GC and conservative pathological predictors remains under questions as Decipher scoring might be inconsistent with up to $20 \%$ GS assessed as $3+3$. Taking the following into consideration, profiling with GC might improve the patients' selection process for AS in low-grade PCa [77]. After collecting convincing evidence, Decipher tool and GC have been recently included in the National Comprehensive Cancer Network guidelines as postprostatectomy tools, while Prolaris and Oncotype DX Prostate were mentioned as biopsy-based tools [78].

ConfirmMDx - Cancer Leaves Epigenetic Fingerprints ConfirmMDx offered by MDxHealth is a quantitative methylation-specific polymerase chain reaction assay panel, measuring GSTP1, APC and RASSF1 derived to detect occult PCa in histopathologically negative biopsies [34]. This methylation assay has been validated in 2 large independent cohorts. In the MATLOC study, the methylation status was a significant independent factor of patient outcome (OR 3.17, 95\% CI 1.81-5.53) and its negative predictive value was superior to standard histopathology reaching as high as $90 \%$ [79]. Since similar data was collected during validation in the DOCUMENT study, epigenetic profiling for GSTP1, APC and RASSF1 emerges as a valuable screening tool especially to reduce unnecessary biopsies [80] and improve biopsy-decision cost-effectiveness. Those capabilities of ConfirmMDx as- 
say are due to methylation field or "halo effect," which is observed in cancer foci: epigenetic DNA changes are present not only in cancer lesions but also in adjacent benign tissues [81, 82]. Epigenetic risk score (EpiScore) for epigenetic aberration in GSTP1, APC and RASSF1 has been recently proposed and combined with traditional clinical risk factors [83] with significant improvement in unnecessary biopsies avoidance and high-grade $\mathrm{PCa}$ identification when compared to currently used metrics. In a recently published paper, GSTP1 hypermethylation on a negative biopsy was highly associated with the risk of PCa on a second biopsy, especially GS $\geq 4+3$ tumours. In the same study, alternative marker-global methylation (LINE1) had a poor predictive value [84]. Although ConfirmMDx aims mainly at identifying significant PCa by improving sensitivity of detection, DNA methylation assays might also be a valuable tool to distinguish PCa from BPH. In the study by Paziewska et al. [85], DNA methylation levels of APC, TACC2, RARB, DGKZ and HES5 promoter regions provided an excellent discrimination between malignant and benign tissues with AUC reaching $0.95-1$. Interestingly, in the same study, standard analysis of gene expression of the best 3 genes (HOXC6, AMACR, and PCA3) yielded only moderate accuracy with AUC $>0.8$ [85]. Simultaneously with growing interest in invasive epigenetic assays, non-invasive methylation biomarkers were evaluated. Zhao et al. [86] have recently identified a panel of 4 methylation biomarkers (APC, CRIP3, GSTP1, and HOXD8) available from urine collected after DRE. Clinical validation is necessary to introduce it to monitor patients on AS [86].

\section{TMPRSS2-ERG - An Androgen-Regulated}

Prostatic BCR-ABL

The recurrent TMPRSS2-ERG (T/E) is an androgen receptor-regulated fusion gene (transmembrane serine protease isoform 2-TMPRSS2 fused with ERG-ETS transcription factor family member gene) observed in about $50 \% \mathrm{PCa}$, which constitutes it as the most common genetic rearrangement observed in this neoplasm [34, 87]. $\mathrm{T} / \mathrm{E}$ is speculated to be a result of repair genes failure [88] and it is found to have an influence on a wide spectrum of signaling pathways. T/E has been proved to induce particular molecular mechanisms involved in metastases development [89], PCa castration-resistance [90] and methylation patterns [91]. TMPRSS2-ERG transcript serves as PCa biomarker detected classically with RT-PCR in urine, although T/E detection rate might be improved significantly by performing an assay both in urine and biopsy material [92]. Addressing the fact that the relation be- tween T/E expression and HGPCa remains unclear [9396] and its prognostic value is constantly questioned [ 95 , 97], Font-Tello et al. [98] have suggested that instead of its mere presence, it is the T/E expression level that corresponds with tumour aggressiveness or prognosis. Moreover, based on meta-analysis from 2014, T/E detection assay (pooled rates of data obtained with RT-PCR) used alone provides unsatisfactory sensitivity of $49 \% \mathrm{PCa}$ detection despite high specificity reaching 90\% [99]. In addition to the above-mentioned information, T/E seems to be a potent predictor of aggressiveness and $\mathrm{BCR}$ when combined with other markers (PCA3) and standard risk calculators $[100,101]$. It might also be used for outcome prediction and selection of patients eligible for systemic treatment [102]. As simultaneous T/E implementation is associated with correction of more than $50 \%$ false negative results of PCA3 when predicting PCa [103], combination of both tests has become a topic of great interest in recent years. T/E-PCA3 urine assay (Mi-Prostate score) is of additional predictive value when added to serum PSA or Prostate Cancer Prevention Trial risk calculator score [104], which has been recently validated in a large prospective cohort [105]. Combined test has the potential to reduce the number of unnecessary biopsies by over $60 \%$ with minimal survival rate change (circa $1 \%$ ) when restricting biopsies to patients with higher PSA levels or individuals with detectable PCA3 or T/E in urine [106, 107].

SChLAP1 - Long Non-Coding RNA Marks Lethal PCa Along with increasing insight into PCa biology, long non-coding RNA (lncRNA) has been hypothesized to be aberrantly expressed in cancerous prostate tissues. After obtaining in vitro and in vivo evidence on its contribution in cancer cell invasiveness and metastasis by antagonizing tumour-suppressive function of chromatin-modifying protein complex [108], one of lncRNAs - SChLAP1 has been proposed as a marker of lethal PCa. The expression of IncRNA can be easily assessed with in situ hybridization; thus, SChLAP1 can be used as a tissue-based biomarker $[34,109]$. SChLAP1, expressed at higher levels, has been proved to correlate with disease progression and poor outcome after radical prostatectomy in patients with localized PCa [109]. The test was validated in multi-institutional studies in predicting both metastases [34, 110] and disease-specific survival $[34,111]$. Although clinical evidence on SChLAP1 in situ hybridization is being constantly updated, its prognostic features for prediction of pathologic outcome, metastases, BCR and survival have already been confirmed by meta-analysis [112]. Since the 
assay shows particular potential in detecting aggressive forms of $\mathrm{PCa}$, it has recently been proposed as a biomarker of unfavourable subpathologies in localized disease [113]. With these encouraging properties, IncRNA has the potential to serve as a stratification tool for surveillance in patients of highest risk.

\section{Will Urine Exosome Assays Reduce the Number of} Unnecessary Biopsies?

What has been a significant limitation of transcript tests is the lability of mRNA outside cellular environment. Simultaneously with advances in RNA purification techniques, a novel method of isolating PCA3 and ERG transcripts encapsulated in exosomes has been developed [42]. The rationale for replacing standard methods with the extraction of exosomal RNA comes from protective properties of exosome and its particular mRNA expression patterns, which are highly representative for the cell of the origin $[114,115]$. Initial experience with urine-derived EXO106 score (the sum of normalized PCA3 and ERG transcript levels normalized to SPDEF) has constituted exosomal RNA extraction as a promising tool to discriminate PCa from healthy individuals [42]. With a negative predictive value of $97.5 \%$ within "gray zone" serum, PSA in the $2-10 \mathrm{ng} / \mathrm{mL}$ range EXO106 score has emerged as a promising tool to aid initial biopsy decision-making [42]. Exosome gene expression assay was then externally validated in the prospective, multisite trial under the name ExoDx Prostate Intelliscore $[34,116]$. With expression levels cut-points set in training cohort, $27 \%$ biopsies in independent "gray zone" cohort would have been avoided, missing only $5 \%$ of patients with HGPCa. With this significant clinical benefit, ExoDx Prostate Intelliscore might not only aid in decision making on initial biopsy but also be supportive in repeated-biopsy population and patients undergoing AS. Thus, full spectrum of clinical utility of exosome expression assays is yet to be established.

\section{NADiA ProsVue - to Detect Undetectable PSA}

NADiA is an immunoassay derived to detect PSA nucleic acid in serum [117]. The test is based on immunopolymerase chain reaction with 2 monoclonal antibodies employed - one conjugated to DNA label and the other to paramagnetic microparticles. After the removal of excess reporter conjugate (magnetic capture) and several re-suspension cycles, PSA concentrations are determined. As limit of quantification drops to $0.65 \mathrm{pg} / \mathrm{mL}$, which is >tenfold lower than ultrasensitive PSA immunoassays, immuno-polymerase chain reaction can be considered the most sensitive commercial PSA test. NADiA might be used to determine PSA kinetics at very low concentrations and thus constitutes an efficient post-RP stratifying tool. ProsVue PSA slope $\leq 2 \mathrm{pg} / \mathrm{mL} / \mathrm{month}$ has been proposed as a prognostic factor of $\mathrm{PCa}$ clinical recurrence reduced risk that might also be of additional predictive value when used with established risk factors [118, 119]. In reanalysis from 2014, NADiA was also predictive of reduced PCaspecific mortality risk [119]. Post-RP stratification with NADiA seems to be particularly valuable in individuals in whom secondary therapy is considered, as it may help to avoid unnecessary treatment. Indeed, in multicentre, riskstratified cohort ProsVue PSA slope $\leq 2 \mathrm{pg} / \mathrm{mL} /$ month reduced secondary treatment recommendations (ART or ADT), which in turn implied possible health-care costs reduction [120]. However, in cost-effectiveness analysis, ProsVue impact on costs is speculated to depend on the extent to which ART will be reduced in patients with low risk of recurrence and remains uncertain when related to quality-adjusted life years [121]. Although ProsVue received US premarket clearance in 2011, it is yet to be approved by FDA.

\section{Circulating Cell-Free Tumour DNA - Next}

Generation Sequencing for "Liquid Biopsy"

Next Generation Sequencing (NGS), an extremely efficient sequencing approach, provides an opportunity to transfer the outcomes of research on mutational changes in PCa directly to the clinic. The main rationale for seeking cell-free tumour DNA (cfDNA) in serum lies in heterogeneity of regional chromosomal DNA ploidy between cancer patients and healthy individuals, and has been raised long ago [122]. Although it is present also in healthy individuals' serum [123], the amount of cfDNA released during cancerogenesis differs significantly [124]. qRT-PCR for cfDNA can be helpful in differentiating PCa from $\mathrm{BPH}$ within particular PSA levels [125], but the analytic process is long and toilsome. cfDNA NGS, especially massive parallel sequencing, provides great statistical power, which could also be successfully utilized to distinguish between $\mathrm{PCa}$ and prostatitis or healthy individuals [126]. NGS measurements use copy number variation converted into copy number instability score as accurate hallmark of malignant transformation [127]. Currently, Chronix Biomedical is validating NGS-based blood test using copy number instability on cfDNA in the prospective clinical trial on 1,500 men referred for a prostate biopsy after abnormal PSA test or DRE. The study is expected to complete its patient accrual in mid-2017 and announce results in early 2018 (https://clinicaltrials.gov/ ct2/show/NCT02771769). 


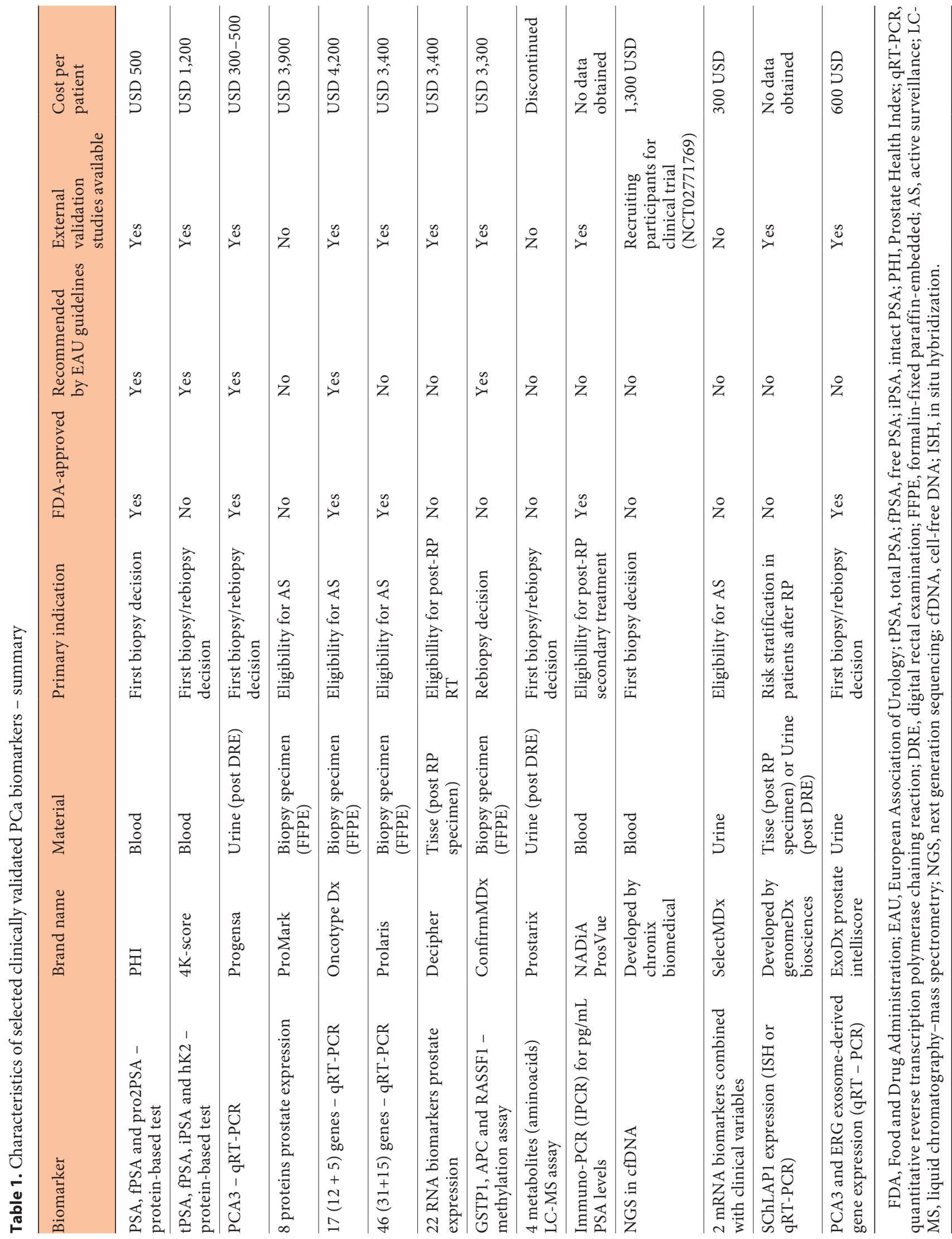


SelectMDx - Simple Transcript Panel, Complicated Algorithm and Non-Stand-Alone Test

SelectMDx is the algorithm combining qRT-PCR for 2 mRNA molecules (HOXC6 and DLX1) with clinical parameters (PSA, PSAD, DRE, age and family history of $\mathrm{PCa}$ ) in order to predict the presence of significant $\mathrm{PCa}$. Both analyzed transcripts were chosen out of 39 biomarkers identified in the previous gene expression profiling study [128]. Interestingly, in the same study combination of HOXC6, DLX1 (used in SelectMDx) and TDRD1 was suggested to outperform $(A U C=0.81)$ Progensa PCA 3 assay $(\mathrm{AUC}=0.68)$ and serum PSA $(\mathrm{AUC}=$ 0.72 ) when predicting $\mathrm{GS} \geq 7 \mathrm{PCa}$. Implementation of HOXC6 and DLX1 into the algorithm resulted in improving HG PCa predictive accuracy with AUC reaching 0.90 in the validation cohort [129]. In this recent multicentre prospective study, SelectMDx outperformed Progensa as well as Prostate Cancer Prevention Trial risk calculator. In fact, some controversies that arose around the PCA3 assay as single transcript marker [100] seem to catalyze the evaluation of transcript panel tests like SelectMDx. Based on the preliminary data, SelectMDx can emerge as a supportive prostate biopsy decision tool. Although biomarker-based risk score might be promising, some concerns should be named. First clinical validation has been performed, yet further evaluation and external validation are greatly expected, as our recent knowledge is limited practically to 2 studies. The fact that SelectMDx becomes predictively valuable only after combining with other parameters, might be considered a limitation in itself. Although the algorithm outperforms PCA3 analyzed exclusively, one should notice that the construction of nomogram based on PCA3 and clinical data has also been undertaken in some already-mentioned studies [52, 55]. Comparison between these tools and SelectMDx is yet to be performed.

\section{Conclusion}

In recent years, there has been an increased in PCa biomarker research activities, which was backed by numerous new validation studies (Table 1). Together with emerging prospective updates, more often, the question about PSA replacement or its supplementation is being raised. Most of the tests presented here aim at outperforming markers, nomograms and calculators used to date or supply additional value to them. Based on current knowledge, not every described assay is eligible for population screening, but most show at least interesting po- tential as stratifying, differentiating and prognostic tools. There are also factors that are limiting further progress. Price and availability are some such factors. With an average cost of 500 USD per measurement, now they do not meet one of the most important conditions of a screening test. Utility of biomarkers as decision-supporting tools often seems to be limited by lack of clear indications on further clinical proceeding. Defining cut-offs in large validation cohorts and calibrating test-based scores are not helpful in solving the issue. Similar problems are faced by clinicians when using nomograms - stratifying patients as exhibiting high risk of reaching a particular end-point is not equal to diagnosing this end-point. At the same time, there is also growing competition from multiparametric MRI, which provides binary and usually straightforward detection of PCa both in primary and rebiopsy settings. Having considered the above factors, it seems that PSA will stay with us in the immediate future, but the future of these new technologies remains unclear.

\section{Disclosure Statement}

No conflicts of interest have been declared by the authors.

Financial Sources

No funding has been obtained for this study.

References

1 Arnold M, Karim-Kos HE, Coebergh JW, Byrnes G, Antilla A, Ferlay J, et al: Recent trends in incidence of five common cancers in 26 European countries since 1988: analysis of the European cancer observatory. Eur J Cancer Oxf Engl 1990. 2015;51:1164-1187.

2 Schröder FH, Hugosson J, Roobol MJ, Tammela TLJ, Zappa M, Nelen V, et al: Screening and prostate cancer mortality: results of the European Randomised Study of Screening for Prostate Cancer (ERSPC) at 13 years of followup. Lancet Lond Engl 2014;384:2027-2035.

3 Andriole GL, Crawford ED, Grubb RL, Buys SS, Chia D, Church TR, et al: Prostate cancer screening in the randomized prostate, lung, colorectal, and ovarian cancer screening trial: mortality results after 13 years of followup. J Natl Cancer Inst 2012;104:125-132.

4 Thompson IM, Pauler DK, Goodman PJ, Tangen CM, Lucia MS, Parnes HL, et al: Prevalence of prostate cancer among men with a prostate-specific antigen level < or $=4.0 \mathrm{ng}$ per milliliter. N Engl J Med 2004; 350:2239-2246. 
5 Sangster-Guity N, Tu-Sekine B, Raben DM, Denmeade SR, Williams SA: Mutational analysis of prostate-specific antigen defines the intrinsic proteolytic activity of the proPSA zymogen. Prostate 2016;76:1203-1217.

6 Lee YJ, Park JE, Jeon BR, Lee SM, Kim SY, Lee YK: Is prostate-specific antigen effective for population screening of prostate cancer? A systematic review. Ann Lab Med 2013;33: 233-241.

7 Bjurlin MA, Mendhiratta N, Wysock JS, Taneja SS: Multiparametric MRI and targeted prostate biopsy: improvements in cancer detection, localization, and risk assessment. Cent Eur J Urol 2016;69:9-18.

8 Mottet N, Bellmunt J, Bolla M, Briers E, Cumberbatch MG, De Santis M, et al: EAUESTRO-SIOG guidelines on prostate cancer. Part 1: screening, diagnosis, and local treatment with curative intent. Eur Urol 2017;71: 618-629.

9 Vickers AJ, Savage C, O'Brien MF, Lilja H: Systematic review of pretreatment prostatespecific antigen velocity and doubling time as predictors for prostate cancer. J Clin Oncol 2009;27:398-403.

10 Patel HD, Feng Z, Landis P, Trock BJ, Epstein JI, Carter HB: Prostate specific antigen velocity risk count predicts biopsy reclassification for men with very low risk prostate cancer. J Urol 2014;191:629-637.

11 Loeb S, Metter EJ, Kan D, Roehl KA, Catalona WJ: Prostate-specific antigen velocity (PSAV) risk count improves the specificity of screening for clinically significant prostate cancer. BJU Int 2012;109:508-513; discussion 513-514.

12 Loeb S, Bruinsma SM, Nicholson J, Briganti A, Pickles T, Kakehi Y, et al: Active surveillance for prostate cancer: a systematic review of clinicopathologic variables and biomarkers for risk stratification. Eur Urol 2015;67:619-626.

13 Christensson A, Björk T, Nilsson O, Dahlén U, Matikainen MT, Cockett AT, et al: Serum prostate specific antigen complexed to alpha 1 -antichymotrypsin as an indicator of prostate cancer. J Urol 1993;150:100-105.

14 Catalona WJ, Partin AW, Slawin KM, Brawer MK, Flanigan RC, Patel A, et al: Use of the percentage of free prostate-specific antigen to enhance differentiation of prostate cancer from benign prostatic disease: a prospective multicenter clinical trial. JAMA 1998;279: 1542-1547.

15 Khan MA, Sokoll LJ, Chan DW, Mangold LA, Mohr P, Mikolajczyk SD, et al: Clinical utility of proPSA and 'benign' PSA when percent free PSA is less than 15\%. Urology 2004; 64:1160-1164.

16 Foj L, Filella X, Alcover J, Augé JM, Escudero JM, Molina R: Variability of assay methods for total and free PSA after WHO standardization. Tumour Biol J Int Soc Oncodevelopmental Biol Med 2014;35:1867-1873.

17 Faria EF, Carvalhal GF, dos Reis RB, TobiasMachado M, Vieira RAC, Reis LO, et al: Use of low free to total PSA ratio in prostate can- cer screening: detection rates, clinical and pathological findings in Brazilian men with serum PSA levels $<4.0 \mathrm{ng} / \mathrm{mL}$. BJU Int 2012; 110(11 pt B):E653-E657.

18 Masieri L, Minervini A, Vittori G, Lanciotti M, Lanzi F, Lapini A, et al: The role of free to total PSA ratio in prediction of extracapsular tumor extension and biochemical recurrence after radical prostatectomy in patients with PSA between 4 and $10 \mathrm{ng} / \mathrm{ml}$. Int Urol Nephrol 2012;44:1031-1038.

19 Sokoll LJ, Sanda MG, Feng Z, Kagan J, Mizrahi IA, Broyles DL, et al: A prospective, multicenter, National Cancer Institute Early Detection Research Network study of [-2] proPSA: improving prostate cancer detection and correlating with cancer aggressiveness. Cancer Epidemiol Biomarkers Prev 2010;19:1193-1200.

20 Guazzoni G, Nava L, Lazzeri M, Scattoni V, Lughezzani G, Maccagnano C, et al: Prostatespecific antigen (PSA) isoform p2PSA significantly improves the prediction of prostate cancer at initial extended prostate biopsies in patients with total PSA between 2.0 and 10 $\mathrm{ng} / \mathrm{ml}$ : results of a prospective study in a clinical setting. Eur Urol 2011;60:214-222.

21 Heijnsdijk EAM, Denham D, de Koning HJ: The cost-effectiveness of prostate cancer detection with the use of prostate health index. Value Health 2016;19:153-157.

22 de la Calle C, Patil D, Wei JT, Scherr DS, Sokoll L, Chan DW, et al: Multicenter evaluation of the prostate health index to detect aggressive prostate cancer in biopsy naïve men. J Urol 2015;194:65-72.

23 Hori S, Blanchet JS, McLoughlin J: From prostate-specific antigen (PSA) to precursor PSA (proPSA) isoforms: a review of the emerging role of proPSAs in the detection and management of early prostate cancer. BJU Int 2013;112:717-728.

24 Lazzeri M, Abrate A, Lughezzani G, Gadda GM, Freschi M, Mistretta F, et al: Relationship of chronic histologic prostatic inflammation in biopsy specimens with serum isoform [-2] proPSA (p2PSA), \%p2PSA, and prostate health index in men with a total prostate-specific antigen of $4-10 \mathrm{ng} / \mathrm{ml}$ and normal digital rectal examination. Urology 2014;83:606-612.

25 Lazzeri M, Haese A, Abrate A, de la Taille A, Redorta JP, McNicholas T, et al: Clinical performance of serum prostate-specific antigen isoform [-2]proPSA (p2PSA) and its derivatives, \%p2PSA and the prostate health index (PHI), in men with a family history of prostate cancer: results from a multicentre European study, the PROMEtheuS project. BJU Int 2013;112:313-321.

26 De Luca S, Passera R, Fiori C, Bollito E, Cappia S, Mario Scarpa R, et al: Prostate health index and prostate cancer gene 3 score but not percent-free prostate specific antigen have a predictive role in differentiating histological prostatitis from $\mathrm{PCa}$ and other nonneoplastic lesions (BPH and HG-PIN) at repeat biopsy. Urol Oncol 2015;33:424.e17-e23.
27 Lughezzani G, Lazzeri M, Buffi NM, Abrate A, Mistretta FA, Hurle R, et al: Preoperative prostate health index is an independent predictor of early biochemical recurrence after radical prostatectomy: results from a prospective single-center study. Urol Oncol 2015;33:337.e7-e14.

28 Cantiello F, Russo GI, Ferro M, Cicione A, Cimino S, Favilla V, et al: Prognostic accuracy of prostate health index and urinary prostate cancer antigen 3 in predicting pathologic features after radical prostatectomy. Urol Oncol 2015;33:163.e15-e23.

29 Fossati N, Buffi NM, Haese A, Stephan C, Larcher A, McNicholas T, et al: Preoperative prostate-specific antigen isoform $\mathrm{p} 2 \mathrm{PSA}$ and its derivatives, \%p2PSA and prostate health index, predict pathologic outcomes in patients undergoing radical prostatectomy for prostate cancer: results from a multicentric European prospective study. Eur Urol 2015; 68:132-138.

30 Porpiglia F, Russo F, Manfredi M, Mele F, Fiori C, Bollito E, et al: The roles of multiparametric magnetic resonance imaging, PCA3 and prostate health index-which is the best predictor of prostate cancer after a negative biopsy? J Urol 2014;192:60-66.

31 Porpiglia F, Cantiello F, De Luca S, Manfredi M, Veltri A, Russo F, et al: In-parallel comparative evaluation between multiparametric magnetic resonance imaging, prostate cancer antigen 3 and the prostate health index in predicting pathologically confirmed significant prostate cancer in men eligible for active surveillance. BJU Int 2016;118: 527-534.

32 Gnanapragasam VJ, Burling K, George A, Stearn S, Warren A, Barrett T, et al: The prostate health index adds predictive value to multi-parametric MRI in detecting significant prostate cancers in a repeat biopsy population. Sci Rep 2016;6:35364.

33 Carlsson S, Maschino A, Schröder F, Bangma C, Steyerberg EW, van der Kwast T, et al: Predictive value of four kallikrein markers for pathologically insignificant compared with aggressive prostate cancer in radical prostatectomy specimens: results from the European Randomized Study of Screening for Prostate Cancer section Rotterdam. Eur Urol 2013;64:693-699.

34 McGrath S, Christidis D, Perera M, Hong SK, Manning T, Vela I, et al: Prostate cancer biomarkers: are we hitting the mark? Prostate Int 2016;4:130-135.

35 Voigt JD, Zappala SM, Vaughan ED, Wein AJ: The Kallikrein Panel for prostate cancer screening: its economic impact. Prostate 2014;74:250-259.

36 Vedder MM, de Bekker-Grob EW, Lilja HG, Vickers AJ, van Leenders GJLH, Steyerberg EW, et al: The added value of percentage of free to total prostate-specific antigen, PCA3, and a kallikrein panel to the ERSPC risk calculator for prostate cancer in prescreened men. Eur Urol 2014;66:1109-1115. 
37 Nordström T, Vickers A, Assel M, Lilja H, Grönberg H, Eklund M: Comparison between the four-kallikrein panel and prostate health index for predicting prostate cancer. Eur Urol 2015;68:139-146.

38 Stattin P, Vickers AJ, Sjoberg DD, Johansson $\mathrm{R}$, Granfors T, Johansson M, et al: Improving the specificity of screening for lethal prostate cancer using prostate-specific antigen and a panel of kallikrein markers: a nested casecontrol study. Eur Urol 2015;68:207-213.

39 Bussemakers MJ, van Bokhoven A, Verhaegh GW, Smit FP, Karthaus HF, Schalken JA, et al: DD3: a new prostate-specific gene, highly overexpressed in prostate cancer. Cancer Res 1999;59:5975-5979.

40 Gezer U, Tiryakioglu D, Bilgin E, Dalay N, Holdenrieder S: Androgen stimulation of PCA3 and miR-141 and their release from prostate cancer cells. Cell J 2015;16:488-493.

41 Deras IL, Aubin SMJ, Blase A, Day JR, Koo S, Partin AW, et al: PCA3: a molecular urine assay for predicting prostate biopsy outcome. J Urol 2008;179:1587-1592.

42 Donovan MJ, Noerholm M, Bentink S, Belzer S, Skog J, O'Neill V, et al: A molecular signature of PCA3 and ERG exosomal RNA from non-DRE urine is predictive of initial prostate biopsy result. Prostate Cancer Prostatic Dis 2015;18:370-375.

43 Zheng K, Dou Y, He L, Li H, Zhang Z, Chen $\mathrm{Y}$, et al: Improved sensitivity and specificity for prostate cancer diagnosis based on the urine PCA3/PSA ratio acquired by sequencespecific RNA capture. Oncol Rep 2015;34: 2439-2444.

44 Auprich M, Bjartell A, Chun FK-H, de la Taille A, Freedland SJ, Haese A, et al: Contemporary role of prostate cancer antigen 3 in the management of prostate cancer. Eur Urol 2011;60:1045-1054.

45 Crawford ED, Rove KO, Trabulsi EJ, Qian J, Drewnowska KP, Kaminetsky JC, et al: Diagnostic performance of PCA3 to detect prostate cancer in men with increased prostate specific antigen: a prospective study of 1,962 cases. J Urol 2012;188:1726-1731.

46 Gittelman MC, Hertzman B, Bailen J, Williams T, Koziol I, Henderson RJ, et al: PCA3 molecular urine test as a predictor of repeat prostate biopsy outcome in men with previous negative biopsies: a prospective multicenter clinical study. J Urol 2013;190:64-69.

47 van Poppel H, Haese A, Graefen M, de la Taille A, Irani J, de Reijke T, et al: The relationship between prostate cancer gene 3 (PCA3) and prostate cancer significance. BJU Int 2012;109:360-366.

48 Malavaud B, Cussenot O, Mottet N, Rozet F, Ruffion A, Smets L, et al: Impact of adoption of a decision algorithm including PCA3 for repeat biopsy on the costs for prostate cancer diagnosis in France. J Med Econ 2013;16: 358-363.

49 Seisen T, Rouprêt M, Brault D, Léon P, Cancel-Tassin G, Compérat E, et al: Accuracy of the prostate health index versus the urinary prostate cancer antigen 3 score to predict overall and significant prostate cancer at initial biopsy. Prostate 2015;75:103-111.

50 Kaufmann S, Bedke J, Gatidis S, Hennenlotter J, Kramer U, Notohamiprodjo M, et al: Prostate cancer gene 3 (PCA3) is of additional predictive value in patients with PI-RADS grade III (intermediate) lesions in the MR-guided re-biopsy setting for prostate cancer. World J Urol 2016;34:509-515.

51 De Luca S, Passera R, Cattaneo G, Manfredi M, Mele F, Fiori C, et al: High prostate cancer gene 3 (PCA3) scores are associated with elevated Prostate Imaging Reporting and Data System (PI-RADS) grade and biopsy Gleason score, at magnetic resonance imaging/ultrasonography fusion software-based targeted prostate biopsy after a previous negative standard biopsy. BJU Int 2016;118:723-730.

52 Cantiello F, Russo GI, Cicione A, Ferro M, Cimino S, Favilla V, et al: PHI and PCA3 improve the prognostic performance of PRIAS and Epstein criteria in predicting insignificant prostate cancer in men eligible for active surveillance. World J Urol 2016;34:485-493.

53 Hansen J, Auprich M, Ahyai SA, de la Taille A, van Poppel H, Marberger M, et al: Initial prostate biopsy: development and internal validation of a biopsy-specific nomogram based on the prostate cancer antigen 3 assay. Eur Urol 2013;63:201-209.

54 Rubio-Briones J, Borque A, Esteban LM, Casanova J, Fernandez-Serra A, Rubio L, et al: Optimizing the clinical utility of PCA3 to diagnose prostate cancer in initial prostate biopsy. BMC Cancer 2015;15:633.

55 Elshafei A, Chevli KK, Moussa AS, Kara O, Chueh SC, Walter P, et al: PCA3-based nomogram for predicting prostate cancer and high grade cancer on initial transrectal guided biopsy. Prostate 2015;75:1951-1957.

56 Knezevic D, Goddard AD, Natraj N, Cherbavaz DB, Clark-Langone KM, Snable J, et al: Analytical validation of the Oncotype DX prostate cancer assay - a clinical RT-PCR assay optimized for prostate needle biopsies. BMC Genomics 2013;14:690.

57 Klein EA, Cooperberg MR, Magi-Galluzzi C, Simko JP, Falzarano SM, Maddala T, et al: A 17-gene assay to predict prostate cancer aggressiveness in the context of Gleason grade heterogeneity, tumor multifocality, and biopsy undersampling. Eur Urol 2014;66:550-560.

58 Cullen J, Rosner IL, Brand TC, Zhang N, Tsiatis AC, Moncur J, et al: A biopsy-based 17gene genomic prostate score predicts recurrence after radical prostatectomy and adverse surgical pathology in a racially diverse population of men with clinically lowand intermediate-risk prostate cancer. Eur Urol 2015;68:123-131.

59 Cuzick J, Swanson GP, Fisher G, Brothman AR, Berney DM, Reid JE, et al: Prognostic value of an RNA expression signature derived from cell cycle proliferation genes in patients with prostate cancer: a retrospective study. Lancet Oncol 2011;12:245-255.
60 Cuzick J, Berney DM, Fisher G, Mesher D, Møller H, Reid JE, et al: Prognostic value of a cell cycle progression signature for prostate cancer death in a conservatively managed needle biopsy cohort. Br J Cancer 2012;106: 1095-1099.

61 Cooperberg MR, Simko JP, Cowan JE, Reid JE, Djalilvand A, Bhatnagar S, et al: Validation of a cell-cycle progression gene panel to improve risk stratification in a contemporary prostatectomy cohort. J Clin Oncol 2013;31:1428-1434.

62 Bishoff JT, Freedland SJ, Gerber L, Tennstedt P, Reid J, Welbourn W, et al: Prognostic utility of the cell cycle progression score generated from biopsy in men treated with prostatectomy. J Urol 2014;192:409-414.

63 Freedland SJ, Gerber L, Reid J, Welbourn W, Tikishvili E, Park J, et al: Prognostic utility of cell cycle progression score in men with prostate cancer after primary external beam radiation therapy. Int J Radiat Oncol Biol Phys 2013;86:848-853.

64 Cuzick J, Stone S, Fisher G, Yang ZH, North BV, Berney DM, et al: Validation of an RNA cell cycle progression score for predicting death from prostate cancer in a conservatively managed needle biopsy cohort. Br J Cancer 2015;113:382-389.

65 Ukimura O, Gross ME, de Castro Abreu AL, Azhar RA, Matsugasumi T, Ushijima S, et al: A novel technique using three-dimensionally documented biopsy mapping allows precise re-visiting of prostate cancer foci with serial surveillance of cell cycle progression gene panel. Prostate 2015;75:863-871.

66 Sommariva S, Tarricone R, Lazzeri M, Ricciardi W, Montorsi F: Prognostic value of the cell cycle progression score in patients with prostate cancer: a systematic review and meta-analysis. Eur Urol 2016;69:107-115.

67 Karnes RJ, Bergstralh EJ, Davicioni E, Ghadessi M, Buerki C, Mitra AP, et al: Validation of a genomic classifier that predicts metastasis following radical prostatectomy in an at risk patient population. J Urol 2013; 190:2047-2053.

68 Erho N, Crisan A, Vergara IA, Mitra AP, Ghadessi M, Buerki C, et al: Discovery and validation of a prostate cancer genomic classifier that predicts early metastasis following radical prostatectomy. PLoS One 2013;8. http://www.ncbi.nlm.nih.gov/pmc/articles/ PMC3691249/.

69 Badani K, Thompson DJS, Buerki C, Davicioni E, Garrison J, Ghadessi M, et al: Impact of a genomic classifier of metastatic risk on postoperative treatment recommendations for prostate cancer patients: a report from the DECIDE study group. Oncotarget 2013; 4:600-609.

70 Ross AE, Feng FY, Ghadessi M, Erho N, Crisan A, Buerki C, et al: A genomic classifier predicting metastatic disease progression in men with biochemical recurrence after prostatectomy. Prostate Cancer Prostatic Dis 2014; 17:64-69. 
71 Den RB, Yousefi K, Trabulsi EJ, Abdollah F, Choeurng V, Feng FY, et al: Genomic classifier identifies men with adverse pathology after radical prostatectomy who benefit from adjuvant radiation therapy. J Clin Oncol 2015;33:944-951.

72 Klein EA, Yousefi K, Haddad Z, Choeurng V, Buerki C, Stephenson AJ, et al: A genomic classifier improves prediction of metastatic disease within 5 years after surgery in nodenegative high-risk prostate cancer patients managed by radical prostatectomy without adjuvant therapy. Eur Urol 2015;67:778-786.

73 Michalopoulos SN, Kella N, Payne R, Yohannes P, Singh A, Hettinger C, et al: Influence of a genomic classifier on post-operative treatment decisions in high-risk prostate cancer patients: results from the PRO-ACT study. Curr Med Res Opin 2014;30:15471556.

74 Freedland SJ, Choeurng V, Howard L, De Hoedt A, du Plessis M, Yousefi K, et al: Utilization of a genomic classifier for prediction of metastasis following salvage radiation therapy after radical prostatectomy. Eur Urol 2016;70:588-596.

75 Cooperberg MR, Davicioni E, Crisan A, Jenkins RB, Ghadessi M, Karnes RJ: Combined value of validated clinical and genomic risk stratification tools for predicting prostate cancer mortality in a high-risk prostatectomy cohort. Eur Urol 2015;67:326-333.

76 Den RB, Santiago-Jimenez M, Alter J, Schliekelman M, Wagner JR, Renzulli Ii JF, et al: Decipher correlation patterns post prostatectomy: initial experience from 2342 prospective patients. Prostate Cancer Prostatic Dis 2016;19:374-379.

77 Klein EA, Santiago-Jiménez M, Yousefi K, Robbins BA, Schaeffer EM, Trock BJ, et al: Molecular analysis of low grade prostate cancer using a genomic classifier of metastatic potential. J Urol 2017;197:122-128.

78 Mohler JL, Armstrong AJ, Bahnson RR, D'Amico AV, Davis BJ, Eastham JA, et al: Prostate cancer, version 1.2016. J Natl Compr Canc Netw 2016;14:19-30.

79 Stewart GD, Van Neste L, Delvenne P, Delrée P, Delga A, McNeill SA, et al: Clinical utility of an epigenetic assay to detect occult prostate cancer in histopathologically negative biopsies: results of the MATLOC study. J Urol 2013;189:1110-1116.

80 Partin AW, Van Neste L, Klein EA, Marks LS, Gee JR, Troyer DA, et al: Clinical validation of an epigenetic assay to predict negative histopathological results in repeat prostate biopsies. J Urol 2014;192:1081-1087.

81 Truong M, Yang B, Livermore A, Wagner J, Weeratunga $P$, Huang $W$, et al: Using the epigenetic field defect to detect prostate cancer in biopsy negative patients. J Urol 2013;189: 2335-2341.

82 Mehrotra J, Varde S, Wang H, Chiu H, Vargo J, Gray K, et al: Quantitative, spatial resolution of the epigenetic field effect in prostate cancer. Prostate 2008;68:152-160.
83 Van Neste L, Partin AW, Stewart GD, Epstein JI, Harrison DJ, Van Criekinge W: Risk score predicts high-grade prostate cancer in DNA-methylation positive, histopathologically negative biopsies. Prostate 2016;76: 1078-1087.

84 Zelic R, Fiano V, Zugna D, Grasso C, Delsedime L, Daniele L, et al: Global hypomethylation (LINE-1) and gene-specific hypermethylation (GSTP1) on Initial negative prostate biopsy as markers of prostate cancer on a rebiopsy. Clin Cancer Res 2016;22:984-992.

85 Paziewska A, Dabrowska M, Goryca K, Antoniewicz A, Dobruch J, Mikula M, et al: DNA methylation status is more reliable than gene expression at detecting cancer in prostate biopsy. Br J Cancer 2014;111:781-789.

86 Zhao F, Olkhov-Mitsel E, van der Kwast T, Sykes J, Zdravic D, Venkateswaran V, et al: Urinary DNA methylation biomarkers for noninvasive prediction of aggressive disease in patients with prostate cancer on active surveillance. J Urol 2017;197:335-341.

87 Tomlins SA, Rhodes DR, Perner S, Dhanasekaran SM, Mehra R, Sun XW, et al: Recurrent fusion of TMPRSS2 and ETS transcription factor genes in prostate cancer. Science 2005;310:644-648.

88 Thangapazham R, Saenz F, Katta S, Mohamed AA, Tan SH, Petrovics G, et al: Loss of the NKX3.1 tumorsuppressor promotes the TMPRSS2-ERG fusion gene expression in prostate cancer. BMC Cancer 2014;14:16.

89 Tian TV, Tomavo N, Huot L, Flourens A, Bonnelye E, Flajollet $\mathrm{S}$, et al: Identification of novel TMPRSS2:ERG mechanisms in prostate cancer metastasis: involvement of MMP9 and PLXNA2. Oncogene 2014;33: 2204-2214.

90 Cai C, Wang H, Xu Y, Chen S, Balk SP: Reactivation of androgen receptor-regulated TMPRSS2:ERG gene expression in castration-resistant prostate cancer. Cancer Res 2009;69:6027-6032.

91 Geybels MS, Alumkal JJ, Luedeke M, Rinckleb A, Zhao S, Shui IM, et al: Epigenomic profiling of prostate cancer identifies differentially methylated genes in TMPRSS2:ERG fusion-positive versus fusion-negative tumors. Clin Epigenetics 2015;7:128.

92 Bories PN, Younes P, Zerbib M, Denjean L, Popovici T, Cynober L, et al: TMPRSS2-ERG fusion transcripts in matched urine and needle rinse material after biopsy for the detection of prostate cancer. Clin Chem 2013;59: 245-251.

93 Fine SW, Gopalan A, Leversha MA, Al-Ahmadie HA, Tickoo SK, Zhou Q, et al: TMPRSS2-ERG gene fusion is associated with low Gleason scores and not with highgrade morphological features. Mod Pathol 2010;23:1325-1333.

94 Saramäki OR, Harjula AE, Martikainen PM, Vessella RL, Tammela TLJ, Visakorpi T: TMPRSS2:ERG fusion identifies a subgroup of prostate cancers with a favorable prognosis. Clin Cancer Res 2008;14:3395-1400.
95 Gopalan A, Leversha MA, Satagopan JM, Zhou Q, Al-Ahmadie HA, Fine SW, et al: TMPRSS2-ERG gene fusion is not associated with outcome in patients treated by prostatectomy. Cancer Res 2009;69:1400-1406.

96 Eguchi FC, Faria EF, Scapulatempo Neto C, Longatto-Filho A, Zanardo-Oliveira C, Taboga SR, et al: The role of TMPRSS2:ERG in molecular stratification of $\mathrm{PCa}$ and its association with tumor aggressiveness: a study in Brazilian patients. Sci Rep 2014;4: 5640.

97 Martínez-Piñeiro L, Schalken JA, Cabri P, Maisonobe P, de la Taille A; Triptocare Study Group: Evaluation of urinary prostate cancer antigen-3 (PCA3) and TMPRSS2-ERG score changes when starting androgen-deprivation therapy with triptorelin 6-month formulation in patients with locally advanced and metastatic prostate cancer. BJU Int 2014;114:608-616.

98 Font-Tello A, Juanpere N, de Muga S, Lorenzo M, Lorente JA, Fumado L, et al: Association of ERG and TMPRSS2-ERG with grade, stage, and prognosis of prostate cancer is dependent on their expression levels. Prostate 2015;75:1216-1226.

99 Yao Y, Wang H, Li B, Tang Y: Evaluation of the TMPRSS2:ERG fusion for the detection of prostate cancer: a systematic review and meta-analysis. Tumour Biol J Int Soc Oncodevelopmental Biol Med 2014;35:21572166.

100 Leyten GHJM, Hessels D, Jannink SA, Smit FP, de Jong H, Cornel EB, et al: Prospective multicentre evaluation of PCA3 and TMPRSS2-ERG gene fusions as diagnostic and prognostic urinary biomarkers for prostate cancer. Eur Urol 2014;65:534-542.

101 Sabaliauskaite R, Jarmalaite S, Petroska D, Dasevicius D, Laurinavicius A, Jankevicius F,etal:CombinedanalysisofTMPRSS2-ERG and TERT for improved prognosis of biochemical recurrence in prostate cancer. Genes Chromosomes Cancer 2012;51:781791.

102 Reig Ò, Marín-Aguilera M, Carrera G, Jiménez N, Paré L, García-Recio $S$, et al: TMPRSS2-ERG in blood and docetaxel resistance in metastatic castration-resistant prostate cancer. Eur Urol 2016;70:709-713.

103 Robert G, Jannink S, Smit F, Aalders T, Hessels D, Cremers R, et al: Rational basis for the combination of PCA3 and TMPRSS2:ERG gene fusion for prostate cancer diagnosis. Prostate 2013;73:113120.

104 Tomlins SA, Aubin SMJ, Siddiqui J, Lonigro RJ, Sefton-Miller L, Miick S, et al: Urine TMPRSS2:ERG fusion transcript stratifies prostate cancer risk in men with elevated serum PSA. Sci Transl Med 2011;3:94ra72.

105 Tomlins SA, Day JR, Lonigro RJ, Hovelson DH, Siddiqui J, Kunju LP, et al: Urine TMPRSS2:ERG Plus PCA3 for individualized prostate cancer risk assessment. Eur Urol 2016;70:45-53. 
106 Salami SS, Schmidt F, Laxman B, Regan MM, Rickman DS, Scherr D, et al: Combining urinary detection of TMPRSS2:ERG and PCA3 with serum PSA to predict diagnosis of prostate cancer. Urol Oncol 2013; 31:566-571.

107 Merdan S, Tomlins SA, Barnett CL, Morgan TM, Montie JE, Wei JT, et al: Assessment of long-term outcomes associated with urinary prostate cancer antigen 3 and TMPRSS2:ERG gene fusion at repeat biopsy. Cancer 2015;121:4071-4079.

108 Prensner JR, Iyer MK, Sahu A, Asangani IA, Cao Q, Patel L, et al: The long noncoding RNA SChLAP1 promotes aggressive prostate cancer and antagonizes the SWI/SNF complex. Nat Genet 2013;45:1392-1398.

109 Mehra R, Shi Y, Udager AM, Prensner JR, Sahu A, Iyer MK, et al: A novel RNA in situ hybridization assay for the long noncoding RNA SChLAP1 predicts poor clinical outcome after radical prostatectomy in clinically localized prostate cancer. Neoplasia $\mathrm{N}$ Y N 2014;16:1121-1127.

110 Prensner JR, Zhao S, Erho N, Schipper M, Iyer MK, Dhanasekaran SM, et al: RNA biomarkers associated with metastatic progression in prostate cancer: a multi-institutional high-throughput analysis of SChLAP1. Lancet Oncol 2014;15:1469-1480.

111 Mehra R, Udager AM, Ahearn TU, Cao X, Feng FY, Loda M, et al: Overexpression of the long non-coding RNA SCHLAP1 independently predicts lethal prostate cancer. Eur Urol 2016;70:549-552.

112 Ma W, Chen X, Ding L, Ma J, Jing W, Lan T, et al: The prognostic value of long noncoding RNAs in prostate cancer: a systematic review and meta-analysis. Oncotarget 2017, Epub ahead of print.

113 Chua MLK, Lo W, Pintilie M, Murgic J, Lalonde $\mathrm{E}, \mathrm{Bhandari} \mathrm{V}$, et al: A prostate cancer 'nimbosus': genomic instability and SChLAP1 dysregulation underpin aggression of intraductal and cribriform sub- pathologies. Eur Urol 2017, Epub ahead of print.

114 Nilsson J, Skog J, Nordstrand A, Baranov V, Mincheva-Nilsson L, Breakefield XO, et al: Prostate cancer-derived urine exosomes: a novel approach to biomarkers for prostate cancer. Br J Cancer 2009; 100:1603-1607.

115 Skog J, Würdinger T, van Rijn S, Meijer DH, Gainche L, Sena-Esteves M, et al: Glioblastoma microvesicles transport RNA and proteins that promote tumour growth and provide diagnostic biomarkers. Nat Cell Biol 2008;10:1470-1476.

116 McKiernan J, Donovan MJ, O'Neill V, Bentink S, Noerholm M, Belzer S, et al: A novel urine exosome gene expression assay to predict high-grade prostate cancer at initial biopsy. JAMA Oncol 2016;2:882-889.

117 McDermed JE, Sanders R, Fait S, Klem RE, Sarno MJ, Adams TH, et al: Nucleic acid detection immunoassay for prostate-specific antigen based on immuno-PCR methodology. Clin Chem 2012;58:732-740.

118 Moul JW, Lilja H, Semmes OJ, Lance RS, Vessella RL, Fleisher $M$, et al: NADiA ${ }^{\circledR}$ ProsVueTM PSA slope is an independent prognostic marker for identifying men at reduced risk for clinical recurrence of prostate cancer after radical prostatectomy. Urology 2012;80:1319-1325.

119 Moul JW, Sarno MJ, McDermed JE, Triebell MT, Reynolds MA: NADiA ProsVue prostate-specific antigen slope, CAPRA-S, and prostate cancer - specific survival after radical prostatectomy. Urology 2014;84: 1427-1432.

120 Moul JW, Chen DYT, Trabulsi EJ, Warlick CA, Ruckle HC, Porter JR, et al: Impact of NADiA ProsVue PSA slope on secondary treatment decisions after radical prostatectomy. Prostate Cancer Prostatic Dis 2014; $17: 280-285$.

121 Reed SD, Stewart SB, Scales CD, Moul JW: A framework to evaluate the cost-effectiveness of the NADiA ProsVue slope to guide adjuvant radiotherapy among men with high-risk characteristics following prostatectomy for prostate cancer. Value Health 2014; 17:545-554.

122 Stroun M, Anker P, Lyautey J, Lederrey C, Maurice PA: Isolation and characterization of DNA from the plasma of cancer patients. Eur J Cancer Clin Oncol 1987;23:707-712.

123 Beck J, Urnovitz HB, Riggert J, Clerici M, Schütz E: Profile of the circulating DNA in apparently healthy individuals. Clin Chem 2009;55:730-738.

124 Allen D, Butt A, Cahill D, Wheeler M, Popert R, Swaminathan R: Role of cell-free plasma DNA as a diagnostic marker for prostate cancer. Ann N Y Acad Sci 2004; 1022:76-80

125 Feng J, Gang F, Li X, Jin T, Houbao H, Yu C, et al: Plasma cell-free DNA and its DNA integrity as biomarker to distinguish prostate cancer from benign prostatic hyperplasia in patients with increased serum prostate-specific antigen. Int Urol Nephrol 2013;45: 1023-1028.

126 Schütz E, Akbari MR, Beck J, Urnovitz H, Zhang WW, Bornemann-Kolatzki K, et al: Chromosomal instability in cell-free DNA is a serum biomarker for prostate cancer. Clin Chem 2015;61:239-248.

127 Heitzer E, Ulz P, Belic J, Gutschi S, Quehenberger F, Fischereder K, et al: Tumor-associated copy number changes in the circulation of patients with prostate cancer identified through whole-genome sequencing. Genome Med 2013;5:30.

128 Leyten GHJM, Hessels D, Smit FP, Jannink SA, de Jong H, Melchers WJG, et al: Identification of a candidate gene panel for the early diagnosis of prostate cancer. Clin Cancer Res 2015;21:3061-3070.

129 Van Neste L, Hendriks RJ, Dijkstra S, Trooskens G, Cornel EB, Jannink SA, et al: Detection of high-grade prostate cancer using a urinary molecular biomarker-based risk score. Eur Urol 2016;70:740-748. 